\title{
Т.П. Калашникова
}

\section{НЕВРОЛОГИЧЕСКИЕ И НЕЙРОПСИХОЛОГИЧЕСКИЕ ПРОЯВЛЕНИЯ СПЕЦИФИЧЕСКИХ РАССТРОЙСТВ ОБУЧЕНИЯ У ДЕТЕЙ}

\author{
Пермская государственная медицинская академия
}

Р е фе р а т. Изучены клинические и нейропсихологические проявления специфических расстройств обучения в процессе длительного наблюдения за учащимися общеобразовательной пкколы с 1 по 5-й класс с попыткой выделения основных прогностически неблагоприятных факторов в развитии дисграфии и дислексии. Специфические расстройства обучения являются достаточно стойкими. Регресс симптомов к 5-му классу наступил липь у 4 детей. У $50 \%$ школьников появились вторичные невротические жалобы. Прогностически неблагоприятными для развития расстройств обучения являются феномен зеркального написания, выявляющийся в 1-2-м классах, нарушение пространственных представлений, слухового восприятия, в том числе фонематического слуха, У большинства пациентов имелось сочетание резидуально-органического поражения головного мозга, отягощенного наследственного анамнеза дисграфией и неблагоприятными социальными факторами.

\section{Т. П. Калашникова}

БАЛАЛАРНЫ УКЫТКАНДА ҮЗЕНЧӘЛЕК НЕВРОЛОГИК ҺӘМ НЕЙРОПСИХОЛОГИК ТАЙПЫЛЫШЛАР БАРЛЫККА КИЛУ

Дисграфия һәм дислексия үсешендә төп прогностик унайлы булмаган факторларны аерып күрсәтергә омтылып, гомуми белем мәктәпләренен I-V класс укучыларын озакка сузылган күзәтү процессында аларда кличник һәм нейропсихологик тайпылыплар өйрәнелгән. Белем алган чорда укучыларга тына хас булган тайпылыплар нык була. $\mathrm{V}$ класска житкәндә әлеге сиптомнар регрессы бары тик 4 балада гына күзәтелгән. Укучыларның 50 процентында икенчел невротик зарлану барлыкка килгән. I - II классларда ачыклана торган көзгедәй язу феномены, пространстволы күзаллау, ишетеп кабул итү, шул исәптән фонематик ишетү укытуда тайпылышлар үсеше өчен прогностик уңайсыз булып санала. Күпчелек пациентта нәселдәнлек анамнезы дисграфиясе һәм унайсыз социаль факторлар тәэсирендә баш миенең резидуаль-органик зарарлануы да күзәтелгән.

\section{T.P. Kalashnikova}

\section{NEUROLOGIC AND NEUROPSYHOLOGIC MANIFESTATIONS OF SPECIFIC LEARNING DISORDERS IN CHILDREN}

There were studied clinical and neuropsyhologic specific learning disorders of secondary school children from:the $1^{\text {st }}$ to the $5^{\text {th }}$ forms with the aim of finding out the main prognostically unfavourable factors of disgraphia and dislexia development. The specific learning disorders are stable. Regress of symptoms up to the $5^{\text {th }}$ form took place only in 4 children. $50 \%$ of schoolchildren got secondary neurotic complaints. The prognostically unfavourable learning disorders are the following symptoms: phenomen of reflecting writing (observed in 1-2 forms of school), disorders of space impression, of aural perception (including phonematic hearing). Most patients had a combination of residually - organic lesions of brain, family hystory with dysgraphia and unfavourable social factors.

пецифические расстройства обучения внимание исследователей. Они проявляются нарушением чтения, письма, счета, речи. В отечественной литературе эквивалентом понятия "специфические расстройства обучения" используется термин "парциальные нарушения психического развития". Распространенность СРО среди детей довольно велика. В европейских странах, по данным различных авторов, выявляется до $10-25 \%$ детей, имеющих нормальный интеллект [6, 12]. На сегодняшний день СРО изучают в основном с позиций дефектологии и логопедии, то есть преобладает педагогический подход к диагностике и коррекции расстройств чтения, письма и счета. Работ, освещающих данную проблему с клинических позиций, не так много. В болышинстье из них подчеркивается, что слабостью подобных исследований является отсутствие продолжительных наблюдений. Неясными остаются вопросы ранней диагностики, патогенеза, исходов и прогноза СРО, отсутствует их единая классификация $[1,2,4,11,13]$

Целью нашей работы являлось изучение клинических и нейропсихологических проявлений СРО в процессе динамического наблюдения за школьниками с 1 по 5-й класс общеобразова. тельной школы с попыткой выделить прогностически неблагоприятные факторы в раз. витии дислексий и дисграфий.

Нами наблюдались 73 школьника с прояв. лениями дисграфии и дислексии. Дети обучались по различным программам (1 к 3, 1 к 4, 
развивающего обучения). В процессе исследования использовался клинико-анамнестический метод, включающий анализ жалоб, особенности приобретения навыков чтения, письма и счета, анамнез жизни, наследственный анамнез, учитывающий наличие леворукости, недоразвитие устной речи, пограничных психических расстройств у родственников, оценку объективного соматического и неврологического статусов. Все дети были осмотрены психиатром

В нейропсихологическом тестировании применяли методику адаптированного нейропсихологического исследования для : детских неврологов Э.Г.Симерницкой (1988), позволяющей оценивать состояние высших корковых функций [9]. Видеомоторную интеграцию изучали по 11 субтесту методики Векслера. Анализ, общей тревожности оценивали по методике А.Кастанеда (Братислава, 1975) [6]. Кратковременную и отсроченную память исследовали на основании теста на запоминание 10 слов. Уровень школьной мотивации анализировали по результатам́ теста Н.Г.Лускановой [ 8]).

Диагноз дислексии и дисграфии был установлен у школьников на втором году обучения в школе. У 34 (46,6\%) детей были обнаружены сочетанные проявления расстройства чтения и письма, у 22 (30\%) - только дисграфия. Лишь у 7 школьников преобладали расстройства чтения.

Клинические проявления дисграфии носили довольно разнообразный характер. У 36 детей имело место смешение близких по звучанию звуков - оппозиционных ( $6-n, \partial-m$ и. т.д.), неразличение твердых и мягких звуков (моль мол, соль - сол), пропуски букв, особенно гласных. Такой тип нарушения письма можно отнести к акустической дисграфии. В 17 наблюдениях она сочеталась с оптической и проявлялась в замене похожих по написанию букв $(n-m, \sigma-d, \pi-m)$. У 12 школьников, кроме того, имелось расстройство почерка.

Дислексия проявлялась в большинстве случаев (у 18 детей) литеральными парафазиями, нередко с перестановкой слогов. У $13,7 \%$ детей имели место изменения падежных окончаний иं неправильное согласование слов в предложении, что можно расценить как аграмматическую дислексию. У 12 обследованных отмечалось недостаточное понимание прочитанного текста с последующей трудностью пересказа (семантическая дислексия). 5 детей на втором году обучения читали по слогам.

Трудности счета не являлись ведущими, отмечались ко 2-му классу у нескольких детей, проявлялись в основном при переходе через десяток во время устного счета и компенсировались при написании примеров.

У большинства обследованных нами детей были различные жалобы: эмоциональные расстройства (у $58,9 \%$ ), их сочетание с нарушениями сна (у 43,9\%). Жалобы астенического характера определялись у $30(41,1 \%)$ детей. У 26 (35,62\%) учащихся родители и учителя отмечали трудности в концентрации внимания, повышенную отвлекаемость, несобранность, потерю необходимых вещей либо отсутствие их на уроке В $17,8 \%$ случаях это сочеталось с двигательной расторможенностью, импульсивностью Цефалгии, преимущественно головные боли напряжения, реже мигренеподобные, выявлялись у $29(39,7 \%)$ учащихся. У части детей $(21,9 \%)$ имели место патологически привычные действия в виде накручивания волос, онихофагии, различных по характеру тиков.

Важно подчеркнуть, что у 34 (46,6\%) детей жалобы имелись уже до поступления в школу и существенной динамики в течение 1-2-го классов не отмечалось. У 27 (36,9\%) школьников наблюдалось усугубление имевшихся в дошкольном возрасте симптомов, а у $13(17,8 \%)$ детей жалобы появились впервые.

Анализ анамнестических сведений свидетельствует о патологическом течении периода беременности и родов практически у всех обследованных: 3 ребенка родились недоношенными, у 17 детей была асфиксия легкой и средней степени, у 2 - кефалогематома. Однако лишь 19 детей регулярно получали лечение по поводу перинатальной энцефалопатии, в структуре которой преобладали синдром двигательных дисфункций и повышенной нервно-рефлекторной возбудимости. Большинство обследованных статико-моторные навыки приобретали своевременно, лишь трое имели задержку развития большой моторики. Достаточно характерной оказалась задержка развития моторной речи, которая была выявлена у 15 (20,5\%) детей. Формирование фразовой речи отмечалось к 3-4 годам. 
В старшем дошкольном возрасте у 22 (30\%) пациентов имелись расстройства зукопроизношения, которые рассмотривались либо в структуре стертой дизартрии, либо как дислалия. Незначительная часть детей (6 чел.) пंосещала специализированные логопедические группы детского сада. Остальные, как правило, получали консультацию логопеда, несколько занятий по постановке звуков, но регулярное наблюдіение и достаточная по объему логопедическая коррекция отсутствовали.

Изучение наследственного анализа выявило ее отягощенность у $39(53,4 \%)$ детей. У ближайших родственников 17 (23\%) учащихся были сложности в приобретении навыков чтения и письма, у родителей 7 детей на момент обследования имелось расстройство звукопроизношения Наличие леворукости выявилось только в двух семьях, у 2 школьников семейный анамнез был отягощен эпилепсией. Кроме того, $25(34,2 \%)$ детей находились в сложных микросоциальных условиях: неполные семьи, развод родителей, частые ссоры дома.

При изучении объективного статуса у 13 $(17,8$ \%) детей были выявлены множественные стигмы дизэмбриогенеза (гипертелоризм, готическое небо, синдактилия, брахи- либо арахнодактилия, воронкообразная грудная клетка, сандалевидная щель, дисхромия радужной оболочки и т.д.)

Неврологический статус характеризовался рассеянной очаговой симптоматикой - легкими парезами мимических мышц и мышц языка, нистагмом, неуверенностью в выполінении координационных проб, неустойчивостью в позе Ромберга, синдромом Горнера, расстройством мышечного тонуса. Эти симптомы интерпретировались нами как резидуальные явления перенесенной перинатальной энцефалопатии либо миелоэнцефалопатии. У 12 пациентов были выражены вегетативные симптомы - гипергидроз ладоней и стоп с их похолоданием, бледность лица либо его гиперемия, метеотропность, непереносимость транспорта, стойкий красный дермографизм.

Неблагополучие соматического статуса также оказалось характерным для обследованных. 23 ребенка в дошкольном возрасте наблюдались в группе длительно и часто болеющих. У 8 пациентов имелась патология желудочнокишечного тракта, у 5 - функциональная кардиопатия, а у 6 - аллергический дерматит.

При оценке состояния учащихся в 1-м классе В $13,7 \%$ наблюдений (10 детей) обращало на себя внимание наличие феномена зеркального написания (ФЗН), который отсутствовал в группе здоровых школьников. ФЗН проявлялся реверсией направления и изменением формы элементов графической деятельности. По данным литературы, ФЗН изучен недостаточно, однако имеется мнение, что этот феномен отражает нарушение формирования межполушарных взаимоотношений. До шестилетнего возраста его можно рассматривать как своеобразный вариант возрастной нормы [9], а после шести лет происходит качественная перестройка нейродинамических процессов мозга, и ФЗН следует рассматривать как патологический нейропсихологический симптом. Во 2-м классе ФЗН был выявлен у 3 школьников с дисграфией.

Наблюдения за детьми в прощессе обучения до 5-го класса общеобразовательной школы показали следующие закономерности. К 4-5-му классу компенсация симптомов дислексии и дисграфии наступила лишь у 4 детей. У 34 пшкольиков, т.е в 50\% наблюдений, СРО имели место, однако регрессировали или стали значительно менее выражены неврологические жалобы. У 35 (47,9\%) учащихся прослеживалась отрицательная динамика. У 8 из них появились сложности в освоении математики, связанные с осознанием смысла задачи и определением последовательности действий, трудности в изучении устных предметов (история, природоведение, география и т.д.), которые требуют понимание текста и его пересказ. Практически у всех детей этой группы нарастали неврологические жалобы. У 17 из них отмечалось усиление астении, эмоциональной неустойчивости, неуверенности в себе. Дети характеризовали свое состояние так: "я всегда нервничаю”, “Я всегда боюсь сделать что-то не так, вдруг меня будут ругать", “Я всегда чувствую себя уставшим, у меня ни на что нет сил". Некоторые дети реагировали плачем при попытке устного ответа, даже если владели материалом. У 11 школьников стало формироваться конфликтное поведение по отношению к педагогам и однокласникам, что значительно 
усугубляло их социальную дезадаптацию. У четверти пациентов усилились головные боли.

Адаптированный нейропсихологический тест свидетельствует о наличии диспраксии, прежде всего кинестетической и кинетической (динамической). Движения в процессе выполнения теста были диффузными, дети трудно находили ожидаемую позу пальцев, имелись сложности в переключении на другие движения, персеверации.

У большинства отмечалась несформированность пространственных представлений: Нарушалась зрительно-пространственная организация движений с плохой дифференцировкой правой и левой сторон, зеркальным воспроизведением позы. Нарушение пространственного восприятия проявлялось и в рисунках школьников в виде неправильного расположения элементов либо самого рисунка на листе. Обращало внимание отсутствие существенных элементов рисунка, что можно расценивать как элементы коструктивной диспраксии.

Расстройство межанализаторного синтеза выражалось в нарушении видео-моторной координации, снижении скорости образования навыка. Результаты 11 субтеста Векслера у наблюдаемых нами детей составили 7,17: $+0,86$ стен, а в контрольной группе - 10,33 + 1,22. У 35 обследованных было нарушено слуховое восприятие ритмов, что проявлялось утратой структуры ритма, особенно сложно было различать серии ударов. Расстройства зрительного гнозиса не были характерными и проявлялись при проведении сенсибилизированных проб (наложенные и схематические изображения).

Изучение данных нейропсихологического исследования в 4-5-м классах показало, чте более стойкими оказались расстройство слухового восприятия, нарушение пространственных представлений и видео-моторной координации, которые и обусловили стойкие проявления дисграфии и дислексии у наблюдаемых нами детей. Объем оперативной и отсроченной памяти на протяжении всех лет наблюдения был нескольқо снижен, хотя кривая графика имела правильную форму. При этом у части детей выявлялись побочные ассоциации в процессе выполнения теста: например, год - лето, сон - ночь, окно стекло, вода - дождь. В некоторых наблюдениях отмечалось стереотипное повторение слов теста, что свидетельствует об инертности речевых следов и было связано с дефицитом функций лобных долей доминантного полушария. В ряде случаев имело место замена звуков и слов, похожих по звучанию (лен - клен, роза - проза, соль - сор, игла - игра), что обусловлено расстройством фонетического восприятия и анализа. Нарушение фонетического слуха, как правило, сочеталось с расстройствами звукопроизношения. Фонетикофонематический фактор является центральным для речевого развития в целом, в том числе для письменной речи. Дефект его формирования может быть следствием дисфункции многих структур мозга - височной доли доминантного полушария, транскортикальных взаимосвязей, стволовых отделов.

В группе школьников с нарастанием клинических симптомов к 5-му классу достоверно увеличивается уровень тревожности в процессе обучения. Показатели теста А.Кастанеды составили $6,66 \pm 0,75$ стен и 9,14 $\pm 1,85$ стен соответственно в 1 и 5-м классах. Также значимой была разница с результатами теста контрольной группы, которые составили 5,5 $\pm 0,29$ стен $(\mathrm{P}<0,05)$. Выявленные расстройства обучения привели к снижению уровня школьной мотивации у детей с СРО. Он составил $18,86 \pm 1,74$ балла (в контрольной группе $-23,5 \pm 4,5$ балла, $\mathrm{P}<0,05)$, при этом доминировала внеучебная мотивация.

Таким образом, результаты наших наблюдений свидетельствуют, что наиболее частым проявлением СРО является дисграфия, которая встречается у $76,6 \%$ детей с трудностями обучения в школе. Дислексия в большинстве случаев сочетается с расстройствами письма и редко выступает как независимый синдром. Клинические проявления СРО достаточно стойки. Регресс симптомов к 5-му классу общеобразовательной школы наступил лишь у 4 детей; у 69 школьников сохранялись признаки дисграфии и дислексии, и у $50 \%$ обусловили формирование вторичных невротических жалоб и усугубление психоэмоционального состояния.

Дискалькулия в 1-2-м классах проявлялась лишь при операциях с переходом через десяток, с дроблением уменьшаемого на составные части, что может быть отражением пространственных нарушений. В последующем преобладали трудности в решении задач, связанные с понима- 
нием условия и усвоением порядка выполнения действий задачи. Это обусловлено расстройством семантического анализа прочитанного текста. Таким образом, расстройство счета выступает в качестве вторичного синдрома.

Анализ этиологических факторов СРО показал, что у большинства детей имеется сочетание резидуально-органического поражения мозга, отягощенного наследственного анамнеза дисграфией и дислексией и неблагоприятных социальных факторов. По нашему мнению, первые два являются более значимыми в патогенезе расстройств высших корковых функций. Социальное неблагополучие служит лишь усугубляющим фактором, так как в данном случае отсутствуют условия для систематического наблюдения и проведения коррекционных меропрятий в достаточном объеме. Прогностически неблагоприятными для развития СРО можно выделить ряд синдромов, которые появляются первыми или бывают достаточно стойкими: это ФЗН, имеющийся у детей в 1-2-м классах, нарушение пространственных представлений, слухового восприятия, в том числе расстройство фонематического слуха.

\section{ЛИТЕРАТУРА}

1. Баранов А.А. //Российский педиатрический журнал. 1999. - № 2. - C. 4 -6.
2. Вассерман Л.И.,Дорофеева С.А.,Меерсон Я.А. Методы нейропсихологической диагностики. - СПб, 1997.

3. Величко М.А., Ковязина М.С. Особый ребенок, исследования и опыт помощи./ Мат. семинара “Организация службы социально-психологической службы детям с острой пкольной дезадаптацией и их семьям." М., 4-7 мая 1998 г. - Вып 1. - С. 27-34.

4. Ильин А.Г., Степанова М.И., Рапопорпт И.К. и др. // Российский педиатрический журнал. - 1999. - № 5. C. $14-22$.

5. Калапникова Л.А., Кадыков А.С., Кашина Е.М. и др. // Неврол. журн. - 2000. - Т.5. - №1. - С. 15-21.

6. Кастанеда А., Мак-Кэндлесс Б, Палермо Д. С. Психодиагностические и дидактические тесты. Братислава, 1975.

7. Корнев А.Н. Нарушения чтения и письма у детей. СПб, 1997.

8. Лусканова Н.Г. Методы исследования детей с трудностями в обучении. - М., 1993

9. Осипенко Т.Н. Психоневрологическое развитие доткольников. - М., 1996.

10.Симерницкая Э.Г. Методика адаптированного нейропсихологического исследования для детских неврологов. / Метод. реком. - М., 1988.

11. Халецкая О.В., Трошин В.М. Минимальные дисфункции мозга в детском возрасте. - Н.Новгород, 1995.

12. Fergusson D. M. // J. Child. Psychol. Psychiatry. 1997. - Vol. 38 (6) - P. 633-644.

13. Gordon N. Brain-dev. - 1991. - may 13(3). P. $143-147$.

Поступила 13.02.01 